Case Reports
in Dermatology
Case Rep Dermatol 2020;12:119-123

DOI: $10.1159 / 000508490$

Published online: June 18, 2020 (c) 2020 The Author(s)

Published by S. Karger AG, Basel www.karger.com/cde

This article is licensed under the Creative Commons Attribution-NonCommercial 4.0 International License (CC BY-NC) (http://www.karger.com/Services/OpenAccessLicense). Usage and distribution for commercial purposes requires written permission.

\title{
Widespread Hypertrophic Lichen Planus following Programmed Cell Death Ligand 1 Blockade
}

\author{
Caitlyn N. Myrdal $^{a} \quad$ Srinath Sundararajan ${ }^{b} \quad$ Clara Curiel-Lewandrowskic \\ aUniversity of Arizona College of Medicine Tucson, Tucson, AZ, USA; ${ }^{b}$ Hematology and \\ Oncology, Texas Oncology, Houston, TX, USA; 'Department of Dermatology and \\ Oncology, University of Arizona College of Medicine, Banner University Medical Center \\ Tucson, Tucson, AZ, USA
}

\section{Keywords}

Adverse drug reaction - Hypertrophic lichen planus - Immunotherapy · Programmed cell death ligand 1 . Squamous cell carcinoma

\begin{abstract}
Hypertrophic lichen planus (HLP) may not have the typical histological findings of lichen planus and often mimics squamous cell carcinoma (SCC). Distinguishing between the two can pose a diagnostic challenge. Here, we present a case of eruptive HLP mimicking SCC in the context of programmed cell death ligand 1 (PD-L1) immune checkpoint inhibition. A 73-year-old woman recently treated with durvalumab, an anti-PD-L1 antibody, presented to our clinic with diffuse hyperkeratotic papules and plaques previously thought to be eruptive SCC. The lesions did not respond to topical fluorouracil and continued to appear despite discontinuation of immunotherapy. Further histological analysis revealed intraepidermal epithelial proliferation with lichenoid inflammation. Subsequent treatment with topical corticosteroids significantly improved the size and number of lesions. The diagnosis of HLP was made based on histological features and response to topical steroids in the context of recent immunotherapy. This case reveals HLP as a potential adverse effect of PD-L1 inhibition and highlights the need for additional diagnostic assessment in patients presenting with eruptive hyperkeratotic lesions, especially on the lower extremities.

(C) 2020 The Author(s) Published by S. Karger AG, Basel
\end{abstract}

KARGER

Caitlyn N. Myrdal

University of Arizona College of Medicine Tucson, Class of 2021

7165 N. Pima Canyon Dr.

Tucson, AZ 85718 (USA)

cmyrdal@email.arizona.edu 


\section{Case Reports in Dermatology}

Case Rep Dermatol 2020;12:119-123

DOI: $10.1159 / 000508490$

C 2020 The Author(s). Published by S. Karger AG, Basel www.karger.com/cde

Myrdal et al.: Widespread HLP following PD-L1 Blockade

\section{Introduction}

Hypertrophic lichen planus (HLP) is a T cell-mediated reactive inflammatory disease whose precise etiology is unknown. HLP is a clinically distinct variant of lichen planus, and often does not share typical histological findings [1]. Most patients with HLP present with numerous hyperkeratotic pruritic papules and plaques, commonly on the lower extremities. The hyperkeratosis and scale frequently seen with HLP lesions may clinically resemble squamous cell carcinoma (SCC). The clinical context including lesion symptomatology, recent chemotherapy or immunotherapy use, as well as response to topical corticosteroids may be helpful in distinguishing between the two entities. A delay in diagnosis and treatment of severe eruptions may lead to discontinuation or postponement of immunotherapy. This case highlights that HLP should be considered as a diagnosis in patients with recent history of immune checkpoint inhibition who present with hyperkeratotic papules and plaques.

\section{Case Report}

A 73-year-old woman presented to us with a 6-month history of numerous scaly, papular lesions on bilateral legs, forearms, and chest. One year prior, she was diagnosed with stage IIIA lung adenocarcinoma for which she received chemotherapy and 6 months of maintenance therapy with durvalumab, an anti-programmed cell death ligand 1 (PD-L1) monoclonal antibody. The patient noticed the lesions 2 months after initiation of durvalumab therapy and continued to notice new lesions after durvalumab was discontinued. She was first seen at an outside institution and diagnosed with SCC following biopsy of a left leg lesion. She decided not to proceed with the recommended surgical excision and was referred to our institution. Initial presentation to our clinic revealed 3- to 12-mm hyperkeratotic, erythematous papules and plaques distributed over bilateral legs, anterior thighs, forearms, and chest (Fig. 1a, c).

Histopathologic examination of a lesion on the left leg showed an endophytic well-differentiated squamoproliferative lesion with complex architecture and lichenoid inflammation extending to the biopsy edges (Fig. 1b). Reactive squamous dysplasia and SCC were considered as diagnostic possibilities. Subsequent biopsy of a lesion on the right thigh demonstrated intraepidermal epithelial proliferation with glassy cytoplasm and lichenoid inflammation extending to the tissue edge (Fig. 1d). The lesion lacked the degree of endophytic growth expected of SCC. Lack of definitive diagnostic criteria prompted a 4-week trial of daily topical fluorouracil to the right leg, which offered no improvement in lesion size or number.

A reactive immune process related to PD-L1 blockade was then considered. The patient had continued development of new lesions despite durvalumab cessation, consistent with reports of lichenoid drug eruptions associated with PD-1 inhibitor immunotherapy [2, 3]. Thus, a 3-week course of clobetasol $0.05 \%$ to bilateral lower extremities was trialed and significantly reduced the size and number of lesions. Based on clinicopathologic correlation, a diagnosis of HLP was made.

\section{Discussion}

Durvalumab is a human monoclonal antibody that blocks PD-L1 on tumor cells, preventing T-cell inactivation and allowing for increased cytotoxic response. It is effective for the treatment of unresectable stage III non-small cell lung cancer after chemoradiotherapy [4]. 


\section{Case Reports in Dermatology}

Case Rep Dermatol 2020;12:119-123

DOI: $10.1159 / 000508490$

(c) 2020 The Author(s). Published by S. Karger AG, Basel www.karger.com/cde

Myrdal et al.: Widespread HLP following PD-L1 Blockade

However, potentiating the immune response to cancer also allows for the emergence of unique autoimmune toxicities. Rash, vitiligo, pruritus, and autoimmune exacerbation are among the most common dermatologic immune-related adverse effects (irAEs) reported with anti-PD-L1 therapy. Most low-grade dermatologic irAEs are successfully treated with topical corticosteroids or oral antihistamines, but higher-grade irAEs may require high-dose corticosteroids or cessation of immunotherapy. Histologic examination of rash associated with immune checkpoint inhibitors often shows lichenoid dermatitis, and cases of eruptive HLP in the context of anti-programmed cell death protein 1 (PD-1) inhibitors, pembrolizumab and nivolumab, have been reported $[2,3,5]$. However, the development of eruptive HLP in the context of anti-PD-L1 therapy, such as durvalumab, is not well described. Interestingly, there are multiple reports highlighting the development of oral lichenoid eruptions in association with PD-L1 blockade [6]; however, to our knowledge, there are no reported cases of eruptive cutaneous HLP in the context of PD-L1 blockade.

HLP may masquerade as SCC and complicate diagnosis, particularly when few lesions are present. Histological findings of HLP often mimic SCC [7, 8]. Examination of HLP may demonstrate irregular acanthosis, horn cyst formation, and moderate dyskeratosis, making it difficult to distinguish from SCC [1]. Additionally, typical histological manifestations of lichen planus may not be present in HLP, such as hypergranulosis and basal cell vacuolar degeneration [9]. As seen in our case, the diagnosis of SCC should be carefully reconsidered when multiple hyperkeratotic lesions occur in a short period of time in a patient with recent immunotherapy use. Furthermore, immune checkpoint inhibitors are not typically associated with the development of SCC and even represent a therapeutic option for advanced disease [10]. Thus, the initial diagnosis of multiple eruptive cutaneous SCC in this case was in conflict with the history of recent PD-L1 blockade. Based on this context, histologic findings, and positive response to topical steroid treatment, a diagnosis of HLP was favored.

This case highlights that patients presenting with hyperkeratotic lesions or squamous dysplasia in the context of anti-PD-L1 therapy should be considered for additional diagnostic assessment. The importance of distinguishing HLP from SCC is imperative in avoiding unnecessary surgery and providing prompt and effective treatment. Additionally, early recognition and management of HLP may prevent discontinuation of immunotherapy, a potentially lifeprolonging treatment for patients with advanced malignancies.

\section{Acknowledgments}

We thank the pathologists involved in the interpretation of the histology as well as providing the histology slides used in this report, especially Dr. Tracy Davis of Dermpath Diagnostics, Tucson, AZ, Arizona. We would also like to thank Delaney Stratton, DNP, FNP-BC, for her contribution to this report.

\section{Statement of Ethics}

This research complies with the guidelines for human studies and was conducted ethically in accordance with the World Medical Association Declaration of Helsinki. The patient gave written consent for the publication of this information, including the publication of images. 


\section{Case Reports in Dermatology}

\section{Disclosure Statement}

The authors have no conflicts of interest to declare.

\section{Funding Sources}

No funding was received for this work.

\section{Author Contributions}

Caitlyn Myrdal, Srinath Sundararajan, and Clara Curiel-Lewandrowski each participated in acquiring data, writing and editing the report, and are in agreement with the publication of the paper.

\section{References}

1 Tan E, Malik R, Quirk CJ. Hypertrophic lichen planus mimicking squamous cell carcinoma. Australas J Dermatol. 1998 Feb;39(1):45-7.

2 Goldinger SM, Stieger P, Meier B, Micaletto S, Contassot E, French LE, et al. Cytotoxic cutaneous adverse drug reactions during anti-PD-1 therapy. Clin Cancer Res. 2016 Aug;22(16):4023-9.

3 Hwang SJ, Carlos G, Wakade D, Byth K, Kong BY, Chou S, et al. Cutaneous adverse events (AEs) of antiprogrammed cell death (PD)-1 therapy in patients with metastatic melanoma: A single-institution cohort. ] Am Acad Dermatol. 2016 Mar;74(3):455-61.e1.

4 Antonia SJ, Villegas A, Daniel D, Vicente D, Murakami S, Hui R, et al.; PACIFIC Investigators. Durvalumab after chemoradiotherapy in stage III non-small-cell lung cancer. N Engl J Med. 2017 Nov;377(20):1919-29.

5 Fontecilla NM, Kittler NW, Lopez A, Yang C, Geskin L. Programmed cell death protein-1 inhibitor-induced granuloma annulare and hypertrophic lichen planus masquerading as squamous cell carcinoma. JAAD Case Rep. 2018 Jul;4(7):636-9.

6 Sibaud V, Eid C, Belum VR, Combemale P, Barres B, Lamant L, et al. Oral lichenoid reactions associated with anti-PD-1/PD-L1 therapies: clinicopathological findings. J Eur Acad Dermatol Venereol. 2017 Oct;31(10):e464-9.

7 Dietert JB, Rabkin MS, Joseph AK. Squamous cell carcinoma versus hypertrophic lichen planus; a difficult differential diagnosis of great significance in approach to treatment. Dermatol Surg. 2017 Feb;43(2):297-9.

8 Totonchy MB, Leventhal JS, Ko CJ, Leffell DJ. Hypertrophic lichen planus and well-differentiated squamous cell carcinoma: a diagnostic conundrum. Dermatol Surg. 2018 Nov;44(11):1466-70.

9 Levandoski KA, Nazarian RM, Asgari MM. Hypertrophic lichen planus mimicking squamous cell carcinoma: the importance of clinicopathologic correlation. JAAD Case Rep. 2017 Mar;3(2):151-4.

10 Yanagi T, Kitamura S, Hata H. Novel therapeutic targets in cutaneous squamous cell carcinoma. Front Oncol. 2018 Mar;8:79. 


\section{Case Reports in Dermatology}
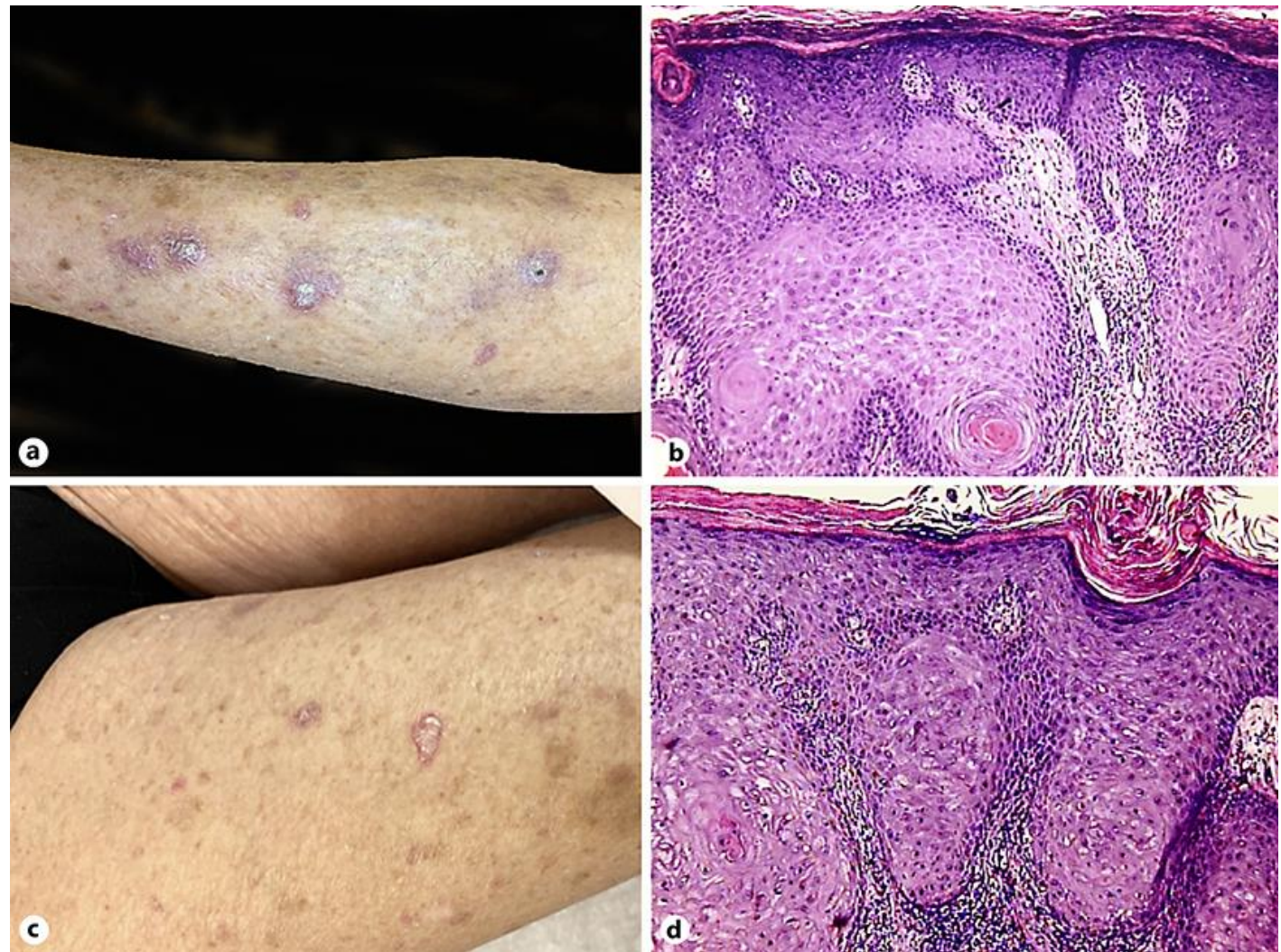

Fig. 1. a Hyperkeratotic lesions on the left lower leg. $\mathbf{b}$ Shave biopsy of lesion on the left lower leg. Hematoxylin-eosin. $\times 10$. $\mathbf{c}$ Lesion on the right anterior thigh. $\mathbf{d}$ Shave biopsy of lesion on the right thigh. Hematoxylin-eosin. $\times 10$. 